\title{
Pursuing Autonomy through Dialogue
}

\author{
Huw Davies \\ Kanda University of International Studies, Chiba, Japan \\ davies-h@kanda.kuis.ac.jp
}

\begin{abstract}
In the Self-Access Learning Center (SALC) at a university in Japan, language learners create and implement individual learning plans. Strategies to facilitate reflective dialogue are used by learning advisors to encourage these learners to pursue their language goals and become increasingly less reliant on direction from their teachers. In this paper, a definition for autonomy is given, and the teaching setting is introduced, giving an overview of the SALC and outlining the ways learners use it, drawing on examples of learners at different stages on their journey to autonomy. After looking at theory and practical applications, this paper demonstrates that guiding learners through dialogue is an appropriate way to challenge meanings and raise consciousness, and move learners towards managing their own language learning.
\end{abstract}

Keywords: self-access, learner autonomy, dialogue, transformational learning.

\section{Introduction \\ The Setting}

This paper is focused on learner-advisor dialogue in the SelfAccess Learning Center (SALC) at a small private university on the eastern edge of the Tokyo metropolis. On a spacious campus, the university has almost 4,000 students, $97 \%$ of whom are undergraduates on four-year courses majoring in foreign languages and international communication. Since 2001, it has had a self-access center, and presently there are ten full-time learning advisors working in the SALC.

The advisors support the student body through optional selfdirected learning courses for credit and noncredit modules; the dialogue that takes place on these courses is largely written. In addition the advisors work on the help desk where learners can drop in with queries, booked 30-minute advising sessions, and more informal advising that takes place around the SALC. The help desk, sessions and informal advising is spoken dialogue. The learners referred to in this paper booked 30-minute advising sessions with the author, who is a learning advisor.

\section{Dialogue and Autonomy}

Dialogue is a fundamental component of learning. Classroom teaching is a dialogue between teacher and learner, and self-study is an internal dialogue within the student. "Every element in an instructional system is either a dialogue (intrapersonal or interpersonal) or a resource which supports dialogue" (Gorsky, Caspi \& Smidt, 2007). The consideration for teachers should not be if they ought 
to use dialogue, but how best to utilize it. In this paper, the focus is on interpersonal dialogue, specifically the dialogue between an educator and a learner.

Two key points should be considered about interpersonal dialogue between a teacher and a student. Firstly, as this dialogue is an essential part of how learning takes place, the teacher's approach should be strategic and considered. Secondly, dialogue is a two-way interaction so the teacher should be focused on listening closely.

The definition of autonomy in language learning has caused much debate. When considering the connection between autonomy and dialogue, it is useful to consider van Lier's (2004) belief that developing autonomy requires the learner to develop their own voice. Another popular definition is "the capacity to take control over learning" (Benson, 2001); moreover, Little has argued that to develop autonomy is to "develop a deep awareness of the learning process, be able to take responsibility, plan, monitor, and evaluate his or her own learning, and to transfer learning to different contexts" (cited in Kato \& Mynard,
2016). The quality of dialogue required to do something as complex as increase awareness and take control or responsibility for one's own learning surely needs to be social rather than internal; increased self-regulation comes as a result of "supportive interpersonal processes" (Ushioda, 2014), it requires support and guidance from others.

A learner who is able to selfregulate displays "the ability to reflect critically on her learning processes, trust her feelings and decisions, reach out for necessary support and resources, recognize, and utilize her negative feelings effectively to establish a continuous learning system" (Yamashita, 2015). To effectively guide learners towards autonomy requires encouraging reflection at a deeper level; fostering autonomy can be viewed as a journey along a trajectory, with learners' continued reflection leading towards a transformational learning experience. Students who use the SALC are at varying places on this continuum, and second language ability is not a good indicator of a student's position or depth of reflection.

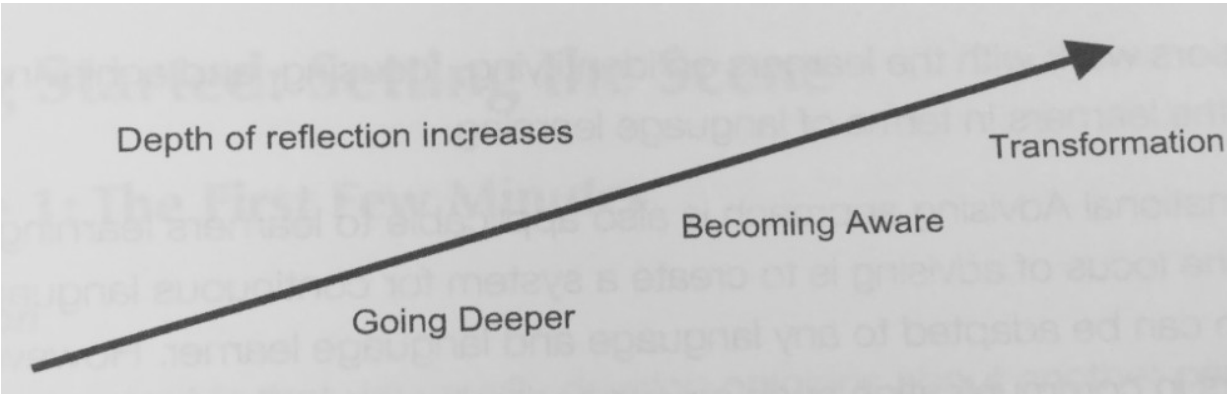

Getting Started

Figure 1. The Learning Trajectory (Kato \& Mynard, 2016). The journey towards autonomy. 


\section{Two Cases - Initial Meetings}

Hana and Maki (both pseudonyms) are students at the university who are at different points in their journey towards autonomy. For Hana, reflecting on her learning is a new thing and in her sessions the advisor was trying to encourage her to think more deeply. Maki is more comfortable with self-reflection and can be found towards the other end of the trajectory.

Hana is a freshman student in her first term at university. From her previous educational experience it is clear that she has not been encouraged to reflect on the language learning process. She is unsure how to manage her learning and has not really thought about how to do it.

Maki is in her third year of university study and a regular user of the SALC. She works in the SALC part-time on the front desk. She has a clear idea of her needs to develop as a language learner.

In her initial advising session, Hana was unfocused, or unable to focus on just one aspect of her learning. She found it difficult to both express her long-term language goal, and reflect on her immediate needs in order to plan her learning in the short-term. She seemed to be looking for the advisor to provide a panacea that would suddenly improve her all-round English skill. She was showing "characteristics of a learner with low metacognitive awareness" (Yamashita, 2015). Ultimately she decided to focus on learning vocabulary to use in conversation.

Maki came to her first session to talk about a piece of writing she had had trouble with. She had already reflected on why she had struggled to write in a different medium, a blog, and used the advisor as a sounding board.

\section{Discussion}

\section{Background to Transformational Dialogue}

Kato and Mynard, drawing on Mezirow, have stated that reflective dialogue can be transformational: learners actively engage themselves to develop and extend their worldview through discourse and reflection (2016).

Reflection is often viewed as interpersonal, a private activity done alone. This lone reflection seldom goes deep enough to be transformative, and reflection through dialogue with a person who supports and challenges is more likely to bring about change (Brockbank, 2009). Self-reflection does not allow as many possibilities to restructure opinions and assumptions (Kato \& Mynard, 2016). Deeper reflection which leads to changes in learning habits and greater autonomy is triggered by dialogue with another.

If autonomy is about taking control of learning, and taking control is a form of seizing power, dialogue can work to change power relations in favor of learners. By engaging students in dialogue about their learning, advisors give previously suppressed voices respect. Reflective dialogue is empowering because "when the learner's desires, wants and dreams are made explicit then there is a realization of what has previously been hidden" (Brockbank, 2009). Reflective dialogue can lead to greater mutual understanding. 
Being listened to is a powerful thing for language learners. As a result of being listened to in an advising session, learners tend to feel comforted and find the circumstances facilitate expressing emotions, beliefs and concerns about learning (Kato \& Mynard, 2016). Being listened to builds intrinsic motivation, which is linked to autonomy and competence (Brockbank, 2009).

\section{Practical Application}

In practice, there are a number of strategies that can intentionally be used to develop a dialogue which encourages deeper reflection from learners. These strategies may already be used instinctively by many teachers, but it is worthwhile for teachers to take control over what they are saying to students and reflect on the effect their words have.

Yuliati (2014) has demonstrated that Indonesian learners of English often fail to communicate because of difficulty Student: I always have to repeat what I say. People never hear the ending of the words. [disappointed tone]

Teacher: They never hear the ending of the words? [copies same disappointed tone]

This strategy can be particularly effective when the advisor feels that the student could be struggling with a motivational or affective issue rather than with the language.

Although it takes some practice, copying the learner's body language is productive in building rapport. Care should be taken when pronouncing consonant clusters. The reaction of many teachers approached by a student worrying about this difficulty would be to try to offer a solution in the form of an activity or a stock piece of advice. This advice may not have the desired effect because the teacher could have missed the student's real meaning, or the student may have heard the same advice before. Additionally, any benefit taken from this teacher's approach would be short term and surface level, the learner would have no input in solving the problem.

A strategic, dialogic approach where the teacher resists preaching would be far more beneficial. Kato and Mynard (2016) have suggested four core strategies for facilitating a reflective dialogue, which will be discussed below, with an Indonesian learner struggling with consonant clusters in mind.

The first strategy is repeating, where the advisor uses an exact phrase the advisee utters, reflecting the tone and intonation. For example:

mirroring that the student does not become aware that the teacher is doing it so a short wait time is advisable, but when done well it helps the learner relax.

Reformulating or restating is similar to repeating, but the statement is recast in the advisor's words. This helps the advisor to clarify the situation and check they have understood, and allows the advisee to look at the same problem from a slightly different viewpoint. For example:

Student: I always have to repeat what I say. People never hear the ending of the words. 
Teacher: So, you are struggling to communicate because people mishear you?

Going through the problem multiple times leads to greater clarity and can help the learner to unravel their concern and find their voice.

Finally, summarizing, or bringing together the main points is effective in both confirming understanding, and in validating the learner - making them feel like they have been listened to.

Teacher: You are finding it difficult to make yourself understood and it is affecting your motivation to speak English. Is that right?

Through following these four strategies, it is possible to promote a deeper reflection from the learner, to get closer to the root of the problem, and to encourage the student to take greater control over deciding and taking the next step.

A deeper reflection occurs when the dialogue allows the advisee to explore their issue more deeply and to become more aware about their situation. Dialogue, as suggested in Figure 1, above, leads towards transformation in how the learner views learning. A preprepared piece of advice from the teacher would not encourage the learner to get started on the learning trajectory.

As well as developing the learner's autonomy, engaging in a reflective dialogue enables the teacher to develop and to ultimately give more appropriate advice. "Teachers have been successful in learning a language but only in their own way" (Cotterall \& Crabbe, 2008), they need to understand other problems and techniques to aid other learners. Cotterall and Crabbe suggest that the way to do this is to keep a record of dialogues with learners and store them in a database in order to "enrich our understanding of the range and nature of possible problems and solutions" (2008). In my own experience as an advisor, learners tend to respond well to suggestions backed up by sharing the successes and experiences of other learners.

\section{Cases - Subsequent Meetings}

In Hana's second advising session she brought along her vocabulary notebook, and seemed to be looking for some kind of teacherly reassurance. However, to encourage movement towards autonomy, she was asked how she felt about what she did, and the strategies restating and repeating were used in order to encourage her to reflect on what she had done and on the effectiveness of her study techniques. This has resulted in her being able to be more expressive in subsequent meetings, suggesting a greater awareness about her learning is developing.

Before coming to her second session with the author, Maki decided for herself a more effective approach to improve her writing, wrote another blog post, then came to talk about why her second piece was better. She was able to critically reflect and come to her own decision on how to develop her writing skill. The strategies to facilitate reflective dialogue used with Maki in her second session allowed her to comprehensively express her thought processes and feelings, to encourage this to become part of a long-term change in her learning habits. 
In both cases, the strategies for reflective dialogue used in the sessions allow the learner to find and develop their own voice. In Hana's case, she is beginning to form and express her feelings and beliefs about her learning for the first time. For

\section{Conclusion and Suggestion}

In many language learning and teaching contexts, not enough time and space is given over to encouraging learners to reflect deeply on their learning. The predicament in many language education settings in Japan and elsewhere is that the short-term need to pass tests overrides the need for long-term personal development for university students. Engaging learners in reflective dialogue has the potential to foster autonomy, to build intrinsic motivation and encourage exploration of language beyond course constraints. Having a SALC and dedicated learning advisors is advantageous, but the four core
Maki, this is an opportunity to give validation to her voice and opinions. These strategies are valuable for promoting autonomy, however aware or autonomous the learner is to begin with.

strategies for reflective dialogue can be adopted by teachers in any setting. I would encourage all language teachers to experiment with these strategies. Reflective dialogue aids learners of all levels, and is beneficial for anyone, however critical or aware of the learning process, and able to self-regulate.

In order to engage learners in reflective dialogue, the teacher should adopt the role of a facilitator (Brockbank, 2009), first building trust and empathy, then allowing the learner to develop their voice. Through continued dialogue over time, the teacher can accompany the student in their pursuit of autonomy.

\section{References}

Benson, P. (2001). Teaching and Researching Autonomy in Language Learning. Harlow, UK: Pearson Education Limited.

Brockbank, A. (2009). The Role of Reflective Dialogue in Transformational Reflective Learning (doctoral dissertation). City University, CASS Business School, London, UK.

Cotterall, S., \& Crabbe, D. (2008). Learners talking: From problem to solution. In T. Lamb \& H. Reinders (Eds.) Learner and teacher autonomy: Concepts, realities and responses (pp. 125-140). Amsterdam, Netherlands: John Benjamins Publishing Company.

Gorsky, P., Caspi, A., \& Smidt, S. (2007). Use of instructional dialogue by university learners in a difficult distance education physics course. Journal of Distance Education, 21(3), 1-22.

Kato, S., \& Mynard, J. (2016). Reflective dialogue: Advising in language learning. New York, NY: Routledge.

Ushioda, E. (2014). Motivation, autonomy and metacognition: Exploring their interactions. In D. Lasagabaster, A. Doiz \& J.M. Sierra (Eds.), Motivation 
and foreign language learning: From theory to practice (pp. 31-49). Amsterdam, Netherlands: John Benjamins Publishing Company.

van Lier, L. (2004). The ecology and semiotics of language learning: $A$ sociocultural perspective. Boston, MA: Kluwer Academic.

Yamashita, H. (2015). Affect and the development of learner autonomy through advising. Studies in Self-Access Learning Journal, 6(1), 62-85.

Yuliati (2014). Final consonant clusters simplification by Indonesian learners of English and its unintelligibility in international context. International Journal of Social Science and Humanity, 4(6), 513-517. 